\title{
Study on the cultivation of College Students' employment consciousness in Major of Physical Education
}

\author{
Wusi Yan $^{1 \mathrm{a}}$ Jun $\mathrm{XiaO}^{2 \mathrm{~b}}$ \\ 1,2 Pingxiang University, Jiangxi 337055, China \\ ’yanwusi@163.com, b423725109@qq.com
}

Key words: employment awareness; physical education; College Students

\begin{abstract}
: with the development of society, the employment situation of sports professional graduates is more and more severe, in addition to improving teaching quality, more important is to cultivate students' awareness of employment, from the students started to carry on the education and training of the sports industry, in order to improve the college students employment ability and finally realize the goal of training professional sports.
\end{abstract}

The 21st Century is an important period of China education reform, the reform of the graduate employment system is a breakthrough in the reform of higher education. The assignment system for college graduates under the planned economic system has been difficult to meet the needs of the new situation and the new employment system to market economy system transition, the formation of the "two-way choice, free profession " because of the training objectives, sports colleges and universities, curriculum and students' own factors and social environment, the employer's ability to absorb and other reasons, the sports college graduates employment rate is low, in the last position in various colleges and universities, the employment of graduates employment difficult, narrow field. This is a very serious problem of graduates our country sports colleges are facing. How to make sports professional graduates to get rid of the predicament and improve the employment rate, in addition to the continuous improvement and reform of teaching system, the cultivation of College Students' employment consciousness is a problem can not be ignored. The society is in need of compound talents of all-round development, and talent training depends on education and students' self-cultivation, training combined. Therefore, the cultivation of College Students' employment consciousness is an important subject of sports colleges.

\section{The situation of college students majoring in Physical Education in China}

According to authoritative statistics, the number of laid-off workers China more than tens of millions, in addition, there are 4 million 800 thousand people in unemployment, the increasingly high demand for people, is tough to find a satisfactory job after graduating from college. Authorities recently published the 44 institutions directly under the Ministry of education of the College graduates, one-time employment rate is $85 \%$ and $54 \%$ in more than and 200 colleges and universities; sports colleges graduates employment rate is only $32.48 \%$, less than half of the same period on the initial employment in Institutions of all kinds.

\section{The current situation of College Students' Employment Consciousness}

Employment awareness refers to the students study at the university level, with their own actions and employment with certain purpose and desire of mental activity. It is the students in learning, work, judgment of things of life in the process of adaptation, work ability, reasonable use of science knowledge, skills and ability to achieve employment summary.

\subsection{The blindness of employment}

Through the investigation, there are $79.83 \%$ professional sports college students on the current employment policies do not understand and do not understand. Fully understand only $20.17 \%$. due 
to lack of awareness of employment policy, employment of college graduates in employment blindness, the choice of the form, there are $87.45 \%$ graduates still hope to "rely on the state to give reasonable arrangement" in college period. Therefore, there is no sense of urgency and Employment anxiety, follow the prescribed order to complete their studies, and once the job comes, it is at a loss what to do, in a passive position.

\section{2 employment consciousness is weak}

At present, the employment of college students awareness of sports colleges is weak, can not learn very well during the design in the University, also did not plan your own understanding goals, but did not take the initiative to develop their own comprehensive capabilities, improve their own quality. Therefore, when the graduation season that they feel the pressure of employment and powerless.

\subsection{The lack of active learning and development of their own potential of the spirit}

Sports professional college students because of their cultural and professional characteristics, the foundation is poor, weak, quite a part of students to learn the lessons to cope, passive learning, to keep up with the study of the standard and the need to pay more than the other students. Therefore, active learning and develop their own potential ability is greatly affected. In addition to professional skills, strong professional knowledge, comprehensive quality, students' knowledge, the depth and breadth of knowledge, humanistic quality is difficult to achieve satisfactory degree. The future employment has caused great influence. All of this, in addition to their own reasons, and the requirements of the students the courses of professional sports colleges and universities, narrow, actively guide and help students develop the knowledge measure not capable of a great relationship.

\subsection{Lack of awareness of competition}

The "two-way choice, freedom of choice." means that the fierce competition for talent, employers to the graduates of the increasingly high demand. The concept of "employment competition" college sports is still vague, there is still a "good basketball, a lifetime to worry about" the only professional idea in four years. The study failed to give full play to their way in the arena, as follows: not think: for employment consideration after four years of little or no consideration; do not move: no initiative to elective courses, the additional skills of foreign language, computer failed to give enough attention, pass rate is low, do: on social activities, class cadre election is not interested, that flower time, effort, affect learning. All of these are the lack of competition consciousness, not from employment, employment deep to consider and develop their own.

\section{The measures and ways to cultivate college students' Employment Consciousness}

\subsection{Strengthen the sports college students' career education and employment guidance}

Job choosing view is a view on social and personnel occupation choice, it includes personal occupation ideal, occupation morality and self working ability and personality. Understanding the concept of career education is to make professional employment, a kind of educational activities to achieve the effect of role transformation of sports colleges and universities should be based on their own. The characteristics, the concept of career education and employment guidance work as a system engineering. Such as: to establish and improve the employment guidance department and the school education, teaching students to adapt to the occupation, education, education of world outlook, the outlook on life education, values education, social practice education and combining with the special guidance personnel, establish employment consulting services and consulting website, make students get more perfect employment guidance by the Department, the formation of sound employment concept, and get a lot of information industry, the Seize the opportunity of employment, with a calm and good attitude, to meet the arrival of the career choice.

\subsection{Break the single training mode, training compound sports talents}

Higher physical education curriculum structure of our current has lagged behind the development of the times. For general weak foundation, basic professional practice narrow; light theory; heavy light skill training course; heavy knowledge light ability. In the course of proportion, the theory of discipline in China accounted for 39\%-55\% that technology accounted for $45 \%-61 \%$, while the developed countries the theory and technology courses is $60 \%-80 \%$ and 
$20 \%-40 \%$. Obviously compared with the developed countries and accounted for $20 \%$ of China's sports college education mode has been difficult to adapt to the development of the society. The analysis of sports colleges in China for university graduates employment difficulties, part the reason lies in the cultivation of the existing curriculum system under the leading talents unity prominent, poor flexibility. Students' knowledge is not open, independent, independent ability, ability to adapt to society.

3.3 Strengthen the comprehensive quality of the training. To meet the needs of the employment of various aspects of employment

At present, the system of employment of graduates is "free choice, two-way choice" in the process of talent competition, the employer of talent quality requirements more and more high, the higher the content of personal knowledge, ability, comprehensive quality is higher, the greater the chance of employment, employment is more secure as a sports college students, not only to master the professional sports skills and knowledge, but also should grasp or understand the relevant professional knowledge closely, broaden their knowledge, increase the weights for career success.

\subsection{Advocate hard-working, dedicated spirit}

Hard work, devotion to their quality is the first quality of success, but also the employer in the examination is very important when the quality of graduates. The hedonistic conditions, about the treatment, payment and conditions in the first place of the college students, the employer can only cause resentment, was rejected. Therefore, graduates must adjust good mentality, ready to endure hardship, once you choose a professional is ready to die for. So as to allow the community to understand you, appreciate you, you can expand the channels of employment, social selection.

\section{5 improve the ability of all kinds of skills}

Foreign language and computer has become an important tool to make a living. Social development requires a variety of talents. Therefore, at the university stage, sports colleges and universities should pay attention to and pay close attention to learning foreign languages and computer grading work, under the rigid index, adopt various methods and standards to supervise students, college students of foreign language, computer bad situation, to enable the students to master the technology, skills, lay a solid foundation for employment.

\section{6 strengthening the education and cultivation of humanistic quality}

The cultural quality and the quality is more and more important in today's society in all walks of life at present, a lot of physical education major students have some sports knowledge and technology, but the lack of Humanities and natural science knowledge and the necessary understanding of the society, the culture and cultural quality is poor, it is difficult to imagine how this the students will face the future social and school quality education. Therefore the Ministry of education requirements, make it become a solid professional skills, professional knowledge and innovation ability, and has a high level of culture, new sports talents.

\section{Summary}

Sports college students, to meet the needs of the talent market in the new century must attach great importance to the training of employment consciousness, strengthen students' career education and employment guidance to establish a correct concept of employment, values and outlook on life. At the same time, the sports colleges and universities education system, curriculum structure should be the development of the times and synchronization, break the culture a single mode, and continuously improve the overall quality of College Students' humanistic quality, only starting from the needs of social development, the requirement of employment of compound talents from the employer, can always stand in the forefront of employment choice in the talent competition, in order to survive in the competition and development. 


\section{Acknowledgments:}

Draft date: 2016-10-1

Fund project: Pingxiang college school subject 《Research on improving the practical ability of students majoring in physical education by cooperative teaching mode under the background of employment》, number: 13PXKY-17

\section{Reference}

[1] Wen-fei Bai, Ling Xu.The employment problem of graduates from Physical Education College of [J]. China sports science and technology.2002 (2)

[2] Zhen-jun Tian, Zhen-bin Li. On the training objectives, training direction and orientation of the professional talents of Higher Physical Education in twenty-first Century [J].Journal of Xi'an Physical Education University.2002 (1)

[3] Xian-guo Liu. Graduates majoring in Physical Education in normal universities in our country employment situation and countermeasure research of [J]. Journal of Xi'an Physical Education University .2002 (2)

[4] Cheng-gang Tan. Psychological analysis of the career choice of college students majoring in physical education [J]. Liaoning sports science and technology.2002 (2)

[5] Yang Qu, Li Du.21 century physical education professional development direction and mode of thinking of [J]..1996 Journal of Beijing Teachers College of Physical Education (1) 